\title{
Ramalina calicaris (L.) Fr. Liken Türünün Antibakteriyel ve Antioksidan Aktivitesi
}

\author{
Antibacterial and Antioxidant Activities of the Lichen Species Ramalina calicaris (L.) Fr.
}

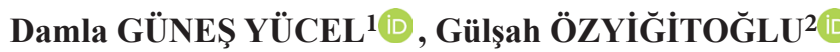 \\ ${ }^{1}$ Marmara Üniversitesi, Fen Bilimleri Enstitüsü, Biyoloji Anabilim Dall, Kadıköy/İstanbul, TÜRKIYYE. \\ ${ }^{2}$ Marmara Üniversitesi, Fen Edebiyat Fakültesi, Biyoloji Bölümü, Kadıköy/İstanbul, TÜRKIYE.
}

Öz

Bu çalışmada Ramalina calicaris (L.) Fr. liken türünün antibakteriyel ve antioksidan aktivitesinin araştırılması amaçlanmıştır. Bolu'da iki farklı lokasyondan (Mudurnu-Aladağlar) toplanmış olan R. calicaris türüne ait liken örnekleri; ayrıştırma ve teşhis yapıldıktan sonra yıkanmış, kurutulmuş ve aseton çözücüsü kullanılarak özütleri çıkarılmıştır. Liken aseton özütlerinin antibakteriyel aktiviteleri iki Gram negatif (CECT 4122 Pseudomonas aeruginosa, ATCC 25922 Escherichia coli) ve iki Gram pozitif (ATCC 29212 Enterococcus faecalis, ATCC 25923 Staphylococcus aureus) bakteri üzerinde disk difüzyon yöntemiyle araştırılmıştır. Araştırma sonucunda aynı ilde iki farklı lokasyondan toplanmış olan liken örneklerine ait özütlerin ikisinin de sadece Gram pozitif olan E. faecalis ve $S$. aureus üzerinde antibakteriyel aktiviteye sahip olduğu, fakat antibakteriyel aktiviteleri arasında çok büyük farklılıklar olmadığı belirlenmiştir. Ayrıca, antibakteriyel etkinliği nispeten daha yüksek bulunan Bolu-Aladağlar lokasyonundan toplanmış olan R.calicaris örneklerinin CUPRAC metodu kullanılarak antioksidan aktivitesi de araştırılmıştır. $R$. calicaris aseton özütünün belirli bir düzeyde kromojenik oksidan indirgeme kapasitesine sahip olduğu, dolayısıyla antioksidan aktivite gösterdiği tespit edilmiştir.

Anahtar Kelimeler: Liken, Ramalina calicaris, antibakteriyel aktivite, antioksidan aktivite

\begin{abstract}
In this study, the antibacterial and antioxidant activities of the lichen species Ramalina calicaris (L.) Fr. were investigated. Lichen samples belonging to $R$. calicaris were collected from two different locations (Mudurnu-Aladağlar) in Bolu. After the separation and the identification steps, the samples were washed, dried and then extracted using an acetone solvent. Antibacterial activities of the acetone extracts were investigated by disk diffusion method on two Gram negative (CECT 4122 Pseudomonas aeruginosa, ATCC 25922 Escherichia coli) and two Gram positive (ATCC 29212 Enterococcus faecalis, ATCC 25923 Staphylococcus aureus) bacteria. As a result of the study, the both extracts of lichen samples collected from two different locations in Bolu had antibacterial activity on only Gram positive E. faecalis and $S$. aureus. However, they did not show a great difference between their antibacterial activities. Antioxidant activity studies were also carried out with $R$. calicaris samples collected from Bolu-Aladağlar location, which indicated relatively higher antibacterial activity by using CUPRAC method. It has been found that $R$. calicaris acetone extract has antioxidant activity as it has a certain level of chromogenic oxidant reduction capacity.
\end{abstract}

Keywords: Lichen, Ramalina calicaris, antibacterial activity, antioxidant activity

\section{GİRIŞ}

Belirli mantarlar ile belirli alg veya siyanobakterilerin mutualist olarak biraraya gelerek oluşturduğu likenlerin çok uzun yıllardır yiyecek, boya maddesi ve kozmetik alanında hammade olarak örneklendirilebilecek kullanımları olduğuna dair bilgiler mevcuttur [1]. Fakat likenlerin antibakteriyel, antioksidan, antiviral, antifungal, antikanser gibi tıbbi alandaki etkinliklerinin araştırılması geleneksel ilaçlar olarak kullanılıyor olmalarından köken almıştır ve likenler üzerinde antibiyotik etkinlik 
araştırmalarının başlangıç tarihi 2. Dünya Savaşı'nın sonrasına tekabül etmektedir [2]. Zaman içinde yapılan araştırmalar sonucu likenlerin bünyesinde likene özgü bir veya birden çok sayıda biyolojik olarak aktif sekonder metabolit bulunduğu ve günümüzde bu liken metabolitlerinin sayısının yaklaşık 1050 civarında olduğu belirlenmiştir [3].

Ramalina cinsinde bulunan likene özgü metabolitler üzerine yapılan araştırmalar; bu cinsin çeşitli türlerinde usnik asit, lekanorik asit, fumarprotosetrarik asit, protosetrarik asit, evernik asit, stiktik asit türevleri ve atranorin gibi çok sayıda sekonder metabolit bulunduğunu göstermiştir [4]. Bu metabolitlere sahip olan Ramalina cinsine ait bazı türlerin de dahil olduğu çeşitli liken türleri ile yapılan antimikrobiyal aktivite araştırmaları, bu metabolitlerin Gram (+) ve Gram (-) bazı bakterilerde dikkate değer ölçüde antimikrobiyal etkiye sahip olduğunu ortaya koymuştur [5-8]. Yine Ramalina cinsinin bazı türleri üzerinde antioksidan aktivite araştırmaları yapılmış ve bu araştırmalardan Ramalina cinsine ait türlerde antioksidan kapasitenin yüksek olduğuna dair sonuçlar elde edilmiştir [9-13].

Günümüzde sentetik maddelerin zararları konusunda bilinç arttıkça insanlar doğala yönelmekte ve sentetik kökenli antioksidanlar daha az tercih edilir hale gelmektedir. Aynı zamanda mevcut antibiyotiklere karşı direnç kazanan bakterilere karşı kullanılabilecek alternatiflerin sayısı gün geçtikçe azalmaktadır. Bu da mikrobiyal hastalıkların antibiyotik tedavisinde önemli bir sorun oluşturmaktadır. Bu bilgiler doğrultusunda, bu çalışmada doğal bir alternatif kaynak olma potansiyeline sahip olan $R$. calicaris liken türünün antibakteriyel ve antioksidan aktivitesinin tespit edilmesi hedeflenmiştir.

\section{MATERYAL VE YÖNTEM}

\section{I. Liken Aseton Özütlerinin Eldesi}

Deneylerde kullanılan $R$. calicaris türü liken örnekleri Bolu ili Mudurnu'dan 24.04.2016 ve Aladağlar'dan 25.04.2016 tarihlerinde toplanmıştır. Örneklerin ayırt edilebilmesi için Mudurnudan toplanan örnekler $R$. calicaris (MUD) ve Aladağlardan toplanan örnekler ise $R$. calicaris (ALA) şeklinde belirtilmiştir. Toplanan örnekler Marmara Üniversitesi, Fen Edebiyat Fakültesi öğretim üyesi Doç. Dr. Gülşah ÖZYİĞITOĞLU tarafından Marmara Üniversitesi Herbaryumu'nda teşhis edilmiştir. Likenlerin tür olarak teşhisi yapıldıktan sonra yabancı maddelerden ayıklanarak y1kanmış ve kurutulmuştur. 3'er gram tartılarak havanda ezilen liken örnekleri toz haline getirilmiş ve steril falkon tüplere alınarak üzerlerine 35 mililitre aseton eklenmiştir. Aseton içerisindeki likenler 24 saat karanlık bir ortamda bekletilmiş ve filtre kağıdıyla süzülerek steril cam petrilere aktarılmıştır. Cam petriler 24 saat çeker ocakta bekletilerek asetonun uçması sağlanmıştır. Aseton uçtuktan sonra kalan toz halindeki liken özütleri kazınarak toplanmış ve steril ependorflara alınmıştır. Steril ve uygun şartlarda muhafaza edilmiş olan toz R. calicaris (ALA) ve R. calicaris (MUD) özütleri antibakteritel ve antioksidan aktivite deneylerinde kullanılmak üzere konsantrasyonları 9 miligram/mililitre olacak şekilde tekrar asetonla çözülerek kullanılmıştır.

\subsection{Bakterilerin Çoğaltılması}

Antibakteriyel aktivite deneyinde kullanılan bakteri suşları (ATCC 29212 E. faecalis, ATCC 25923 S. aureus, CECT 4122 P. aeruginosa, ATCC 25922 E. coli) Yeditepe Üniversitesi Merkez Mikrobiyoloji Laboratuvarı'ndan temin edilmiştir. Bakteri suşları Luria Bertoni (LB) besiyeri kullanılarak üretici firmanın prosedürlerine uygun şartlarda çoğaltılmış ve muhafaza edilmiştir. Deney için kullanılmak üzere stok bakteri kültürlerinden steril şartlarda LB agar besiyeri içeren steril petrilere pasaj alınmış ve $37{ }^{\circ} \mathrm{C}$ 'de 24 saat bekletilerek bakterilerin aktive olmaları sağlanmıştır. Aktive olmuş bakteri kültürlerinden steril özeyle alınan bakteriler LB broth besiyerine eklenmiş ve UV-VIS Spektrofotometre (Beckman Coulter DU 730) kullanılarak bakteri konsantrasyonları $0.5 \mathrm{McF}$ arland'a ayarlanmıştır.

\subsection{Antibakteriyel Aktivite Testleri}

Liken özütlerinin antibakteriyel aktiviteleri disk difüzyon yöntemi kullanılarak araştırılmıştır. Liken aseton özütleri mikropipet kullanılarak $6 \mathrm{~mm}$ çapındaki steril disklere $20 \mu \mathrm{L}, 40 \mu \mathrm{L}$ ve $80 \mu \mathrm{L}$ miktarlarında emdirilmiştir. Emdirme işlemi diskin bir yüzeyine emdirilen asetonun uçması beklenerek aynı işlemin diğer yüzeye uygulanması ve belirlenen miktar emdirilene kadar aynı işlemin tekrarlanması şeklinde gerçekleştirilmiştir. İşlem sonucunda disklerdeki özüt konsantrasyonu; $20 \mu \mathrm{L}$ 'de $0.18 \mathrm{mg}, 40 \mu \mathrm{L}$ 'de 0.36 $\mathrm{mg}$ ve $80 \mu \mathrm{L}$ 'de $0.72 \mathrm{mg}$ olmuştur. LB agar besiyeri içeren steril petrilere $0.5 \mathrm{McF}$ arland konsantrasyonundaki bakterilerden steril şartlarda $35 \mu \mathrm{L}$ ekim yapılmış ve steril cam $\mathrm{L}$ baget ile besiyeri üzerine tamamen yayılması sağlanmıştır. Özüt emdirilmiş diskler ekimi yapılmış olan petrilere steril şartlarda her biri birbirine uygun mesafede olacak şekilde 3'er dozaj olarak yerleştirilmiş ve aynı petrilere karşılaştırma yapmak amacıyla standart antibiyotik diskler de uygun bir mesafede olacak şekilde yerleştirilmiştir. Ekimi yapılmış ve diskleri yerleştirilmiş olan petriler $37^{\circ} \mathrm{C}$ 'de 24 saat inkübe edilmiştir. Bu süre sonunda liken özütü içeren disklerin ve antibiyotik disklerin etrafında oluşan inhibisyon zonlarının çapları cetvel ile ölçülerek kayıt altına alınmıştır. 
Aseton çözücüsünün bakteriler üzerinde inhibe edici etkiye sahip olup olmadığını belirlemek için aseton emdirilmiş ve uçurulmuş diskler kullanılmıştır. Kontrol grubu olarak Gram (-) bakteriler üzerinde Ciprofloxacin $5 \mu \mathrm{g}$, Gram (+) bakteriler üzerinde ise Sulphamethoxazole $25 \mu \mathrm{g}$ antibiyotik diskleri kullanılmıştır. Deneyler 3 tekrarlı olarak çalışılmış ve sonuçlar ortalama değer üzerinden hesaplanmıştır.

\subsection{Antioksidan Aktivite Testleri}

Antioksidan etkinlik araştırması, $R$. calicaris (ALA) ve R. calicaris (MUD) liken örnekleri üzerinde gerçekleştirilen antibakteriyel aktivite testi sonucunda nispeten daha yüksek antibakteriyel aktiviteye sahip olduğu tespit edilen $R$. calicaris (ALA) örnekleri üzerinde yapılmıştır. $R$. calicaris (ALA) aseton özütünün antioksidan etkinliği Apak ve arkadaşları tarafından 2004'te geliştirilen CUPRAC yöntemi ile belirlenmiştir [14]. CUPRAC yöntemi için 3 farklı solüsyon hazırlanmıştır;

$1.0 \times 10^{-2} \mathrm{M}$ olacak şekilde $\mathrm{CuCI}_{2} .2 \mathrm{H}_{2} \mathrm{O} 0,4262 \mathrm{~g}$ tartılıp distile suyla $250 \mathrm{~mL}$ 'ye tamamlanmış, $1.0 \mathrm{M}$ amonyum asetat $19.27 \mathrm{~g}$ tartıllp distile su ile $250 \mathrm{ml}$ 'ye tamamlanmış ve $7.5 \times 10^{-3} \mathrm{M}$ olacak şekilde Neokuproin'den $0.156 \mathrm{~g}$ tartılarak etanolle $100 \mathrm{~mL}$ 'ye tamamlanmıştır.

Bir cam tüp içerisine hazırlanan üç solüsyondan 50'şer $\mu \mathrm{L}$ alınmış ve üzerine $55 \mu \mathrm{L}$ liken özütü koyularak tüp iyice çalkalanmıştır. (CUPRAC metoduna göre toplam $4.1 \mathrm{~mL}$ olması gereken hacim 20'de 1'i olacak şekilde oranlanmıştır.)
AğZı kapatılan tüp oda sıcaklığında 30 dakika bekletilmiştir. Kontrol grubu hazırlanan üç solüsyondan 50 'şer $\mu$ lalınarak ve üzerine $55 \mu \mathrm{l}$ aseton ilave edilerek hazırlanmıştır. 30 dakika sonra örnekler UV spektrofotometrede $450 \mathrm{~nm}$ absorbansta ölçülmüştür. Referans antioksidan olarak troloks kullanılmıştır. Deneyler kontrol grupları kullanılarak ve 3 tekrarlı olarak çalışılmıştır. Elde edilen verilerin ortalamaları ve standart sapmaları belirlenmiştir.

\section{BULGULAR}

\section{I. Antibakteriyel Aktivite}

Çalışmada Bolu ilinde Mudurnu ve Aladağlar lokasyonlarından toplanmış olan $R$. calicaris liken örneklerinin aseton özütlerinin antibakteriyel etkinliğini belirleyebilmek için disk difüzyon yöntemi kullanılmıştır. Steril disklere artan oranlarda emdirilen özüt $E$. faecalis, $S$. aureus, $P$. aeruginosa, E. coli bakterilerine uygulanmıştır. Oluşan zonların çapları diskler dahil şekilde ölçülmüş ve milimetre cinsinden kaydedilmiştir. Asetonun inhibe edici etkinliğini test etmek için hazırlanmış kontrol grubu olan özütsüz disklerde aktivite gözlenmemiştir. Üçer farklı dozda test edilen $R$. $c a$ licaris (ALA)'nın antimikrobiyal aktivite sonuçları Tablo1'de ve $R$. calicaris (MUD) ise Tablo 2'de verilmiştir. Kontrol grubu olarak Gram (-) bakteriler üzerinde Ciprofloxacin $5 \mu \mathrm{g}$ (CIP 5), Gram (+) bakteriler üzerinde ise Sulphamethoxazole $25 \mu \mathrm{g}$ (SXT 25) antibiyotik diskleri kullanılmıştır.

Tablo I. $R$. calicaris (ALA) aseton özütü inhibisyon zonları (mm)

\begin{tabular}{|c|c|c|c|c|c|}
\hline \multirow{2}{*}{ Bakteriler } & \multicolumn{5}{|c|}{ İnhibisyon zonları (mm) } \\
\hline & ALA $0.18 \mathrm{mg}$ & ALA $0.36 \mathrm{mg}$ & ALA $0.72 \mathrm{mg}$ & CIP $5 \mu \mathrm{g}$ & SXT $25 \mu \mathrm{g}$ \\
\hline E. faecalis ATCC 29212 & $11.6 \pm 0.6$ & $12.6 \pm 0.6$ & $13.3 \pm 0.6$ & $\mathrm{D}$ & $24.6 \pm 0.6$ \\
\hline S. aureus ATCC 25923 & $12 \pm 0$ & $13 \pm 0$ & $13.6 \pm 0.6$ & $\mathrm{D}$ & $25.3 \pm 1$ \\
\hline P. aeruginosa CECT 4122 & - & - & - & $32.8 \pm 0.6$ & $\mathrm{D}$ \\
\hline E. coli ATCC 25922 & - & - & - & $25 \pm 0.6$ & $\mathrm{D}$ \\
\hline
\end{tabular}

(-): İnhibisyon yok, D: Denenmedi.

Tablo 2. $R$. calicaris (MUD) aseton özütü inhibisyon zonları (mm)

\begin{tabular}{|c|c|c|c|c|c|}
\hline \multirow{2}{*}{ Bakteriler } & \multicolumn{5}{|c|}{ İnhibisyon zonları (mm) } \\
\hline & MUD $0.18 \mathrm{mg}$ & MUD $0.36 \mathrm{mg}$ & MUD $0.72 \mathrm{mg}$ & CIP $5 \mu \mathrm{g}$ & SXT $25 \mu \mathrm{g}$ \\
\hline E. faecalis ATCC 29212 & $11.3 \pm 1$ & $12 \pm 1.7$ & $13 \pm 1$ & $\mathrm{D}$ & $25 \pm 1$ \\
\hline S. aureus ATCC 25923 & $11 \pm 1$ & $12.3 \pm 0.6$ & $13 \pm 0$ & $\mathrm{D}$ & $25.3 \pm 0.6$ \\
\hline P. aeruginosa $\mathrm{CECT} 4122$ & - & - & - & $33 \pm 0.6$ & $\mathrm{D}$ \\
\hline E. coli ATCC 25922 & - & - & - & $25 \pm 0.6$ & $\mathrm{D}$ \\
\hline
\end{tabular}

(-): İnhibisyon yok, D: Denenmedi. 
R. calicaris (ALA) ve R. calicaris (MUD) aseton özütlerinin uygulanan dozları Gram negatif $P$. aeruginosa ve $E$. coli üzerinde antimikrobiyal aktiviteye sahip olmazken Gram pozitif $E$. faecalis ve $S$. aureus üzerinde belirli büyüklüklerde inhibisyon zonları oluşturarak antibakteriyel aktivite göstermiştir.

R. calicaris (ALA) ve R. calicaris (MUD) örneklerinin her ikisinin de aseton özütlerinin uygulanan dozundaki artışa paralel olarak Gram pozitif $E$. faecalis ve $S$. aureus üzerinde antibakteriyel aktivitede artış gösterdiği tespit edilmiştir.

Deneyde araştırılan bakterilerden kullanılan liken özütlerine karşı en duyarlı olan S. aureus olmuştur. Gram negatif bakterilerin ikisine karşı da herhangi bir antibakteriyel etkinlik tespit edilemezken Gram pozitif bakterilerin ikisine karşı da antibakteriyel etkinlik gözlemlenmesi liken özütlerinin etkinliğinin bakteri hücre duvarının özelliklerine göre değişebileceğini düşündürmektedir.

Test edilen liken özütlerinin hiçbir dozajı mukayese antibiyotiğinden daha yüksek bir antibakteriyel etkinlik göstermemiştir.

\subsection{Antioksidan Aktivite}

R. calicaris (ALA) aseton özütünün antioksidan aktivitesi CUPRAC yöntemiyle belirlenmiştir. Kontrol grubu olarak CUPRAC reaktifine sadece aseton eklenmiştir. Referans antioksidan olarak troloks kullanılmıştır. Troloks kalibrasyon grafiği hazırlanmış, grafikte belirtilen troloks miktarlarının antioksidan etkinliği incelenerek, troloksun miktarına bağlı etkinliğiyle liken özütünün etkinliği orantılanmıştır. Absorbans ve molar derişim grafiğinin eğiminden molar absorplama katsayısı bulunmuş, bulunan bu değer troloksun molar absorplama katsayısına bölünerek troloks eşdeğeri antioksidan kapasitesi bulunmuştur.

R. calicaris (ALA) aseton özütü için CUPRAC yöntemiyle elde edilen sonuç; $5.996 \pm 0.122 \mu \mathrm{g}$ Troloks eşdeğerleri (TE) /g (kuru ağırlık)' dır. Troloksun 5,996 mikrogramının antioksidan etkinliğinin $R$. calicaris (ALA) aseton özütünün 1 gramının antioksidan etkinliğine eşdeğer olduğu belirlenmiştir.

\section{TARTIŞMA VE SONUÇ}

Likenlerin ilaç olarak kullanımları ilk olarak görüntülerinin benzer olduğu organlardaki hastalıklara iyi geleceğine dair bir düşünceyle denenmiş, bu denemelerden bazı ümit verici sonuçlar elde edilmesiyle de likenler ve içeriğinde bulundurduğu kimyasal maddeler bilimsel araştırmaların konusu olmuştur [1]. $R$. calicaris' in geçmiş yıllarda peruk boyası olarak ve sarı - kırmızı yün boyası olarak kullanıldığı bilinmektedir [15]. Ayrıca XX. yüzyılın başlarından beri Avrupa'da kozmetik alanında saç pudrası olarak kullanılmıştır [16]. Bunların yanı sıra; Libya'da Ramalina farinacea, Usnea plicata ve Pseudevernia furfuracea ile birlikte kaynatılarak scı'ba adı verilen geleneksel bir ilaç olarak kullanıldığına dair bilgiler bulunmaktadır [17]. Liken metabolitleri üzerine yapılan araştırmalar sonucu antimikrobiyal, antifungal, antikanser, antiviral, antipiretik, anti-inflamatuar, analjezik ve anti-protozoal gibi pek çok biyolojik aktiviteye sahip olduğu belirlenen usnik asit metaboliti ilk kez 1834 yılında $R$. calicaris'in de aralarında bulunduğu bir kaç liken türünden izole edilmiştir [18].

Çalışmamızda Bolu ilinden toplamış olduğumuz $R$. $c a$ licaris'in aseton özütünün disk difüzyon yöntemiyle Gram pozitif olan E. faecalis ve $S$. aureus üzerinde antibakteriyel aktiviteye sahip olduğu, fakat Gram negatif $E$. coli ve $P$. aeruginosa'ya karşı ise antibakteriyel etkisi bulunmadığı sonucu ortaya çıkmıştır. Ayrıca antioksidan aktivite araştırması CUPRAC yöntemiyle yapılmış olup $R$. calicaris aseton özütünün belirli bir düzeyde kromojenik oksidan indirgeme kapasitesine sahip olduğu, dolayısıyla antioksidan aktivite gösterdiği tespit edilmiştir. Çalışmamızda $R$. calicaris aseton özütünün test edilen Gram pozitif bakterilere karşı antibakteriyel etkinlik gösterirken Gram negatif bakterilere karşı etkinlik göstermemiş olması içerisinde bulunan usnik asit metabolitinin miktarına bağlı olabilir. Çünkü çeşitli çalışmalar usnik asit miktarı yüksek olan liken türlerinin daha yüksek antibakteriyel etkinliğe sahip olduğunu göstermiştir $[\mathbf{1 9 , 2 0 ]}$. R. calicaris aseton özütünün belirli bir seviyede antioksidan etkinliği bulunduğu fakat bu etkinlik seviyesinin diğer bazı liken türlerinden daha düşük olduğu belirlenmiştir [21]. Bunun sebebi bünyesinde bulundurduğu ve antioksidan etkinliği diğer çalışmalarla belirlenmiş olan Sekikaic asit [22] ve Usnik asit [23] miktarına bağlı olabilir. Ayrıca liken bünyesinde bulunan metabolitlerin farklı çözücüler karşısında farklı seviyelerde açığa çıktığı ve bu durumun da araştırılan biyolojik aktiviteler üzerinde etkili olduğu düşünülmektedir [24].

Tay ve ark. (2004) yaptıkları çalışmada $R$. farinacea 'nın aseton özütünün antimikrobiyal etkisini $S$. aureus (ATCC 6538), E. coli (ATCC 25922) ve $P$. aeruginosa (ATCC 27853)'nın da içerisinde bulunduğu çok sayıda bakteri ve mantar üzerinde denemişlerdir. Kirby \& Bauer disk difüzyon yöntemiyle yapılmış olan deneyin sonucunda, çalışmamızda da test edilmiş olan bakterilerden $S$. aureus'a karş1 antibakteriyel etkisi olduğunu, $E$. coli ve $P$. aeruginosa'ya karşı ise antibakteriyel etki bulunmadığını tespit etmişlerdir [25]. Çalışmamızda da $S$. aureus'a karşı antibakteriyel etki elde edilirken, Gram negatif olan E. coli ve P. aeruginosa'ya 
karşı herhangi bir etkinlik görülmemesi çalışma sonuçlar1nın paralel olduğunu göstermektedir.

Çobanoğlu ve ark. (2010) R. farinacea, Platismatia glauca, Evernia divaricata, Bryoria fuscescens ve Alectoria sarmentosa liken türlerinin antibakteriyel etkinliklerini Gram (-) olan P. aeruginosa, Acinetobacter sp. ve E. coli ATCC 11666 bakterileri üzerinde test etmişlerdir. Çözücü olarak kloroform ve aseton kullanmışlardır. Araştırılan liken türlerinin üç bakteri türü üzerinde de farklı seviyelerde etkili olduğu tespit edilmiştir. Çalışmamızda test edilen liken türüyle aynı cinse mensup $R$. farinacea'dan $P$. aeruginosa' ya karşı aseton özütünde, $E$. coli'ye karşı ise kloroform özütünde antibakteriyel etki elde etmişlerdir [26]. Çalışmamıda ise aseton özütüyle bu iki Gram negatif bakteriye karşı da antibakteriyel etki görülememiştir. Çalışmalardan elde edilen sonuçlar arasındaki farklılık çözücülerin farklı olmasından kaynaklanıyor olabilir, çünkü farklı çözücüler liken içindeki farklı metabolitleri etkin hale getirebilmektedir. Aynı zamanda sonuçların farklılığı tür bazındaki farklılıktan, usnik asit miktarlarının farklı olmasından veya deneyin uygulanma metodundan ileri geliyor olabilir.

Sesal ve ark. (2016) Ramalina cinsine mensup R. canariensis, $R$. chondrina, $R$. fastigiata ve $R$. fraxinea türlerinin metanol ve kloroform özütlerinin antimikrobiyal aktivitesini 2 Gram negatif ( $P$. aeruginosa ve E. coli), 2 Gram pozitif bakteri (E. faecalis ve $S$. aureus) ve 1 maya (C. albicans) türüne karşı araştırmışlardır. Gram negatif bakteri türlerine karşı sadece $R$. canariensis ve $R$. chondrina türlerinin kloroform özütleri etkinlik göstermiştir. Aynı zamanda bu iki türün kloroform özütleri $E$. coli üzerinde standart antibiyotikten daha etkili olmuştur. E. faecalis üzerinde sadece $R$. canariensis ve $R$. chondrina türlerinin metanol özütleri hiçbir etkinlik göstermemiştir. $S$. aureus üzerinde 4 liken türüne ait bütün özütler belirli düzeylerde antimikrobiyal etkinlik göstermiştir fakat hiçbiri standart antibiyotikten daha etkili çımamıştır [27]. Çalışmamızda Gram negatif bakterilere (E. coli, P. aureginosa) karşı inhibe edici bir etki elde edilememiş olup, Gram pozitif bakterilere (E. faecalis, S. aureus) karşı ise standart antibiyotikten daha düşük seviyede inhibe edici etki gözlemlenmiştir. Aynı cinse ait bu liken türleri arasındaki antimikrobiyal etkinlik farklılıkları türlerin sahip olduğu sekonder metabolitlerin veya bu metabolitlerin miktarlarının farklı olmasından kaynaklanıyor olabilir. Bu farklılıklar ise sicaklık, $\mathrm{pH}$, kuraklık gibi abiyotik etmenlerden, coğrafi yayılıştan veya küresel 1sınma gibi etmenlerin oluşturduğu çevresel koşullardan, karbon ve nitrojen kaynağının niteliğinden ve hava kirliliğinden ileri geliyor olabilir [28]. Aynı zamanda farklı çözücülerle hazırlanmış özütlerin aynı bakteri üzerinde farklı etki gösteriyor olması çözücülerin bazı sekonder metabolitleri daha etkin ortaya çıkarıyor olabileceğine işaret etmektedir. Bu durumda $R$. calicaris türünün farklı çözücüler kullanılarak elde edilecek özütünün Gram negatif bakteriler üzerinde de etkili olabileceği veya Gram pozitif bakterilere karşı daha yüksek antibakteriyel etki gösterebileceği düşünülebilir.

Zrnzević ve ark. (2017) Ramalina capitata 'nın aseton özütünün antibakteriyel aktivitesini iki Gram pozitif ve üç Gram negatif bakteriye karşı disk difüzyon yöntemini kullanarak test etmişlerdir. Test edilen Gram pozitif bakteriler; Bacillus spizizenii ve $S$. aureus, Gram negatif bakteriler ise; E. coli, P. aeruginosa ve Salmonella abony'dir. Analizler sonucu bu liken türüne ait aseton özütünün Gram pozitif bakterilere karşı yüksek antibakteriyel etkinliği olduğu, Gram negatif bakterilere karşı ise etkinliği olmadığı belirlenmiştir. Test edilen standart antibiyotiğin liken özütüne k1yasla daha yüksek bir etkinliği olduğu belirlenmiştir [21]. Çalışmamızda da $P$. aeruginosa ve E. coli'ye karşı etkinlik oluşmamış ve standart antibiyotik daha etkili çıkmıştır. Elde edilen sonuçlar iki çalışmanın paralel olduğunu ve bu iki türün benzer özellikte olduğunu göstermektedir. Zrnzević ve ark. (2017) aynı çalışmada $R$. capitata 'nın aseton özütünün antioksidan aktivitesini de CUPRAC yöntemiyle test etmişlerdir. Konsantrasyonu $15 \mathrm{mg} / \mathrm{mL}$ olan metanolde çözünmüş özütün toplam antioksidan kapasitesini troloks eşdeğeri cinsinden $6.1176 \pm 0.2964 \mu \mathrm{g}$ Troloks eşdeğerleri (TE) /mg (kuru ağırlık) bulmuşlardır. Çalışmamızda ise konsantrasyonu $9 \mathrm{mg} / \mathrm{mL}$ olan $R$. calicaris (ALA) aseton özütü için elde edilen sonuç; $5.996 \pm 0.122 \mu \mathrm{g}$ Troloks eşdeğerleri (TE) /g (kuru ağırlık)' dır. İki çalışma arasındaki antioksidan etkinlik farkının tür farklılığından kaynaklanacağı gibi, özütlerin konsantrasyon farkından da kaynaklanıyor olabileceği düşünülebilir. Aynı makalede araştırmacılar kendi çalışmalarını Zlatanović ve ark. (2017) tarafından yapılmış güncel bir çalışmayla karşılaştırmışlardır. Bu çalışmada Umbilicaria crustulosa likeninin aseton özütünün troloks eşdeğeri cinsinden tam antioksidan kapasitesi $19.7641 \pm 0.0166$ $\mu \mathrm{g}$ TE / mg bulunmuştur [29]. Araştırmacılar bu türün kendi çalışmış oldukları $R$. capitata örneğinden daha etkili olduğunu belirtmişlerdir, nitekim bizim çalışmamızda test ettiğimiz türden de daha etkilidir. Bu durum kullanılan çözücü ve yöntemin aynı olmasıyla tür bazındaki antioksidan etkinlik farklılığını ortaya koymaktadır.

Sundararaj ve ark. (2015) Ramalina nervulosa likeninin petrol eteri, su ve etanol çözücüleriyle elde edilmiş özütlerinin antioksidan özelliklerini araştırmışlardır. Antioksidan aktiviteyi belirleyebilmek için DPPH, FRAP ve CUPRAC yöntemini kullanmışlardır. Özütlerin $100 \mu \mathrm{g} / \mathrm{mL}$ konsantrasyonda bakır iyonunun $\left(\mathrm{Cu}^{2+}\right)$ indirgeme ölçümlerinden etanol, petroleum eter ve su özütleri için sırasıyla \% 62.49, \% 33.4 ve \% 44.49 sonuçlarını elde etmişlerdir. Aynı çalışmada 
özütün konsantrasyonu arttıkça indirgeme gücünün de arttığı belirlenmiştir [30]. Bu sonuçlara göre, özüt elde etmede kullanılan çözücünün antioksidan etkinlik üzerinde büyük farkl1l1klara neden olduğu görülmektedir. Çözücü olarak bu çalışmada etkili çıkmış olan etanol kullanılarak ve özüt konsantrasyonu arttırılarak $R$. calicaris özütünden de daha yüksek bir antioksidan etkinlik elde edilebileceği düşünülebilir.

Ramalina fastigiata ve $R$. farinacea'nın da bulunduğu 6 liken türünün aseton ve metanol özütlerinin toplam fenol ve antioksidan kapasiteleri Oran ve ark. (2012) tarafindan araştırılmıştır. Ölçümler sonucunda en yüksek antioksidan aktivite değeri $R$. fastigiata'nın metanol özütünde çıkmıştır. $R$. fastigiata'nın metanol özütünün antioksidan aktivite değeri $154.3 \pm 0.2 \mathrm{mg}$ troloks $/ 10 \mathrm{~g}$ örnek iken $R$. farinacea' $\mathrm{nın}$ metanol özütünün antioksidan aktivite değeri $31.7 \pm 0.5 \mathrm{mg}$ troloks/10 g örnek bulunmuştur. Aynı liken türlerinin aseton özütlerinin antioksidan aktivite değerleri ise sırasıyla; $123.9 \pm 0.3 \mathrm{mg}$ troloks $/ 10 \mathrm{~g}$ örnek ve $11.1 \pm 0.9 \mathrm{mg}$ troloks $/ 10$ g örnek bulunmuştur. Çalışmamızda ise $R$. calicaris aseton özütü için bu değer $5.996 \pm 0.122 \mu \mathrm{g}$ Troloks eşdeğerleri (TE) /g örnek olarak bulunmuştur. Sonuçlar karşılaştırılmak üzere orantılandığında en yüksek etkinliği göstermiş olan $R$. fastigiata'nın metanol özütü de aseton özütü de bizim özütümüzden daha etkili çıkmıştır. Aynı cinse mensup R. farinacea'nın da metanol özütü ve aseton özütü bizim özütümüzden daha etkili çıkmıştır. Bu durum tür bazındaki farklılıkların ve çözücü farklı1ıklarının antioksidan aktivite üzerindeki etkisi olarak yorumlanabilir. Aynı liken türü üzerindeki çözücü değişiminden kaynaklanan antioksidan aktivite değeri farklılı̆̆ araştırıcılar tarafindan likenlerin ürettiği sekonder metabolitler farklı kimyasal yapılarda olduğu için organik çözücülerdeki davranışları da değişiklik göstermektedir şeklinde yorumlanmıştır [31]. Örnek verilen çalışmadan elde edilen sonuçlardan hareketle araştırmış olduğumuz $R$. calicaris türünün de metanol çözücüsünde daha yüksek bir antioksidan aktivite gösterebileceği düşünülebilir.

Çok sayıda araştırma, liken örneklerinin yaşam alanındaki iklim, toplandığı rakım, uygulandığı konsantrasyon, özütünün elde edildiği çözücü gibi çok sayıda değişkenin likenin antibakteriyel ve antioksidan etkinliği üzerinde etkili olabileceğini ortaya çıkarmış olup bu koşulların optimal olduğu durumlarda en yüksek etkinin elde edilebileceği düşünülebilir.

Literatür incelendiğinde birçok liken türünün biyolojik aktiviteleriyle ilgili çalışmalar bulunduğu, ancak $R$. calicaris türü üzerinde cinsin diğer türleri kadar araştırmaya rastlanılmadığı için çalışmamız bu türün antibakteriyel ve antioksidan özellikleri ile ilgili yeni veriler sağlamaktadır. Araştırmamız sonucunda $R$. calicaris' in aseton özütlerinin $S$. aureus ve $E$. faecalis Gram pozitif bakterileri üzerinde antibakteriyel etkinliğe sahip olduğu ve aynı zamanda $\mathrm{Cu}(\mathrm{II})$-neokuproin $(\mathrm{Nc})$ reaktifini $\mathrm{Cu}(\mathrm{I})-\mathrm{Nc}$ kelatına indirgeme özelliği göstermesi nedeniyle antioksidan etkinliğe sahip olduğu belirlenmiştir. Çalışma sonuçları, bu liken türünün potansiyel bir antibakteriyel ve antioksidan olarak kullanımının mümkün olduğunu göstermektedir. Karşılaştırma yaptığımız benzer çalışmaların sonuçları; bu liken türünden elde edilmiş olan antibakteriyel ve antioksidan etkinlik değerlerinin daha ileri çalışmalarla arttırılmasının mümkün olduğuna işaret etmektedir. Ülkemizde doğal yetişen bir tür olarak bu liken üzerinde yapılabilecek daha kapsamlı kimyasal çalışmalar sayesinde, ilaç sektöründe kullanılabilecek bir kaynak olma potansiyelinin değerlendirilmesi gereklidir. Bu ve benzeri çalışmalardan elde edilen veriler, hem yaygın bir sorun haline gelmeye başlayan antibiyotiklere dirençli mikroorganizmalara karşı mücadelede hem de doğala yönelim sonucu daha çok tercih edilmeye başlamış olan doğal antioksidan ilaçların elde edilmesinde likenlerden yararlanılmasına katkı sağlayacaktır.

\section{TEŞEKKÜR}

Çalışma boyunca laboratuarından faydalanmamıza olanak veren Doç. Dr. N. Cenk SESAL'a, deney aşamasında hiçbir yardımı esirgemeyen Ezgi UÇARKUŞ ve Barış GÖKALSIN'a çok teşekkür ederiz. Bu makale kapsamında çalışmalara 113S306-COST FA1202 no' lu proje aracılığıyla destek olan TÜBITTAK' a teşekkür ederiz.

\section{KAYNAKLAR}

[1] Çobanoğlu, G., Dilsizoğlu, A., Kavuncuoğlu, Z., \& Oba, D. (2004). Eski ve yeni kullanım alanları, bilinmeyen yönleriyle likenler. Tubitak Bilim ve Teknik Dergisi, 439, 86-89.

[2] Zeybek, U., John, V. (1992). Likenler, kimyasal bileşikleri ve tıbbi kullanımları. Pharmacia, 32 (1) 7.37 - 48.

[3] Molnár, K., \& Farkas, E. (2010). Current results on biological activities of lichen secondary metabolites: a review. Zeitschrift für Naturforschung C, 65(3-4), 157-173.

[4] Şahin, S., Oran, S., Şahintürk, P., Demir, C., Öztürk, Ş. (2015). Ramalina Lichens and Their Major Metabolites as Possible Natural Antioxidant and Antimicrobial Agents. Journal of Food Biochemistry, 39 (4): 471-477.

[5] Francolini, I., Norris, P., Piozzi, A., Donelli, G., \& Stoodley, P. (2004). Usnic acid, a natural antimicrobial agent able to inhibit bacterial biofilm formation on polymer surfaces. Antimicrobial agents and chemotherapy, 48(11), 4360-4365.

[6] Ingolfsdottir, K. (2002). Usnic acid. Phytochemistry, 61(7), 729-736.

[7] Yilmaz, M., Türk, A. O., Tay, T., \& Kivanç, M. (2003). The antimicrobial activity of extracts of the lichen Cladonia foliacea and its (-)-usnic acid, atranorin, and fumarprotocetraric acid 
constituents. Zeitschrift fur Naturforschung. C, Journal of biosciences, 59(3-4), 249-254.

[8] Garcia Rowe, J., Gimenez, G., \& Saenz Rodriguez, M. T. (1999). Some lichen products have antimicrobial activity. Zeitschrift für Naturforschung C, 54(7-8), 605-609.

[9] Sundararaj, J. P., Kuppuraj, S., Ganesan, A., Ponnusamy, P., \& Nayaka, S. (2015). In vitro assesssment of antioxidant and antimicrobial activities of different solvent extracts from lichen Ramalina nervulosa. International Journal of Pharmacy and Pharmaceutical Sciences, 8(8), 200-204.

[10] Kumar, S. P., Kekuda, T. P., Vinayaka, K. S., \& Sudharshan, S. J. (2009). Anthelmintic and antioxidant efficacy of two macrolichens of Ramalinaceae. Pharmacognosy Journal, 1(4), 238-242.

[11] Stanly, C., Hag Ali, D. M., Keng, C. L., Boey, P. L., \& Bhatt, A. (2011). Comparative evaluation of antioxidant activity and total phenolic content of selected lichen species from Malaysia. J Pharm Res, 4, 2824.

[12] Luo, H., Wei, X., Yamamoto, Y., Liu, Y., Wang, L., Jung, J. S., ... \& Hur, J. S. (2010). Antioxidant activities of edible lichen Ramalina conduplicans and its free radical-scavenging constituents. Mycoscience, 51(5), 391-395.

[13] Gulluce, M., Aslan, A., Sokmen, M., Sahin, F., Adiguzel, A., Agar, G., \& Sokmen, A. (2006). Screening the antioxidant and antimicrobial properties of the lichens Parmelia saxatilis, Platismatia glauca, Ramalina pollinaria, Ramalina polymorpha and Umbilicaria nylanderiana. Phytomedicine, 13(7), 515-521.

[14] Apak, R., Güçlü, K., Özyürek, M., \& Karademir, S. E. (2004). Novel total antioxidant capacity index for dietary polyphenols and vitamins $\mathrm{C}$ and $\mathrm{E}$, using their cupric ion reducing capability in the presence of neocuproine: CUPRAC method. Journal of Agricultural and Food Chemistry, 52(26), 79707981.

[15] http://web.uvic.ca/ stucraw/part2NX.html\#Lichens_N-X Erişim tarihi: 08.02.2018.

[16] Hanuš, L. O., Temina, M., \& Dembitsky, V. M. (2008). Antibacterial and antifungal activities of some phenolic metabolites isolated from the lichenized ascomycete Ramalina lacera. Nat Prod Commun, 3, 233-236.

[17] Crawford S.D. (2015). Lichens Used in Traditional Medicine. Chapter 2. In: Lichen Secondary Metabolites - Bioactive Properties and Pharmaceutical Potential (Edited by Rankovic B.). Springer International Publishing, Switzerland. ISBN 978-3-319-13373-7

[18] Moura, J. B., Vargas, A. C. D., Gouveia, G. V., Gouveia, J. J. D. S., Ramos-Júnior, J. C., Botton, S. D. A., ... \& Costa, M. M. D. (2017). In vitro antimicrobial activity of the organic extract of Cladonia substellata Vainio and usnic acid against Staphylococcus spp. obtained from cats and dogs. Pesquisa Veterinária Brasileira, 37(4), 368-378.

[19] Cansaran, D. et al. (2007). HPLC analysis of usnic acid in some Ramalina species from anatolia and investigation of their antimicrobial activities. Pharmaceutical Biology, Vol. 45, No. 1, pp. 77-81.

[20] Shrestha, G., \& St Clair, L. L. (2013). Antimicrobial activity of extracts from two lichens Ramalina menziesii and Usnea lapponica. Bulletin of the California Lichen Society, 20(1), 5-10.

[21] Zrnzevic, I., Stankovic, M., Jovanovic, V. S., Mitic, V., Dordevic, A., Zlatanovic, I., \& Stojanovic, G. (2017). Ramalina capitata (Ach.) Nyl. acetone extract: HPLC analysis, genotoxicity, cholinesterase, antioxidant and antibacterial activity. EXCLI journal, 16, 679.

[22] Luo, H., Wei, X., Yamamoto, Y., Liu, Y., Wang, L., Jung, J. S., ... \& Hur, J. S. (2010). Antioxidant activities of edible lichen Ramalina conduplicans and its free radical-scavenging constituents. Mycoscience, 51(5), 391-395.

[23] Moura, J. B., Vargas, A. C. D., Gouveia, G. V., Gouveia, J. J. D. S., Ramos-Júnior, J. C., Botton, S. D. A., ... \& Costa, M. M. D. (2017). In vitro antimicrobial activity of the organic extract of Cladonia substellata Vainio and usnic acid against Staphylococcus spp. obtained from cats and dogs. Pesquisa Veterinária Brasileira, 37(4), 368-378.

[24] Oran, S., Şahin, S., Öztürk, Ş., Demir, C. (2012). Bazı dalsı ve yapraksı liken türlerinde toplam fenol ve antioksidan kapasite tayini. 21. Ulusal Biyoloji Kongresi, 03-07 Eylül 2012, Ege Üniversitesi, İzmir, Türkiye.

[25] Tay, T., Türk, A. Ö., Y1lmaz, M., Türk, H., \& Kıvanç, M. (2004). Evaluation of the antimicrobial activity of the acetone extract of the lichen Ramalina farinacea and its (+)-usnic acid, norstictic acid, and protocetraric acid constituents. Zeitschrift für Naturforschung C, 59(5-6), 384-388.

[26] Çobanoğlu, G., Sesal, C., Gökmen, B., \& Çakar, S. (2010). Evaluation of the antimicrobial properties of some lichens. South Western Journal of Horticulture, 1(2), 153-158.

[27] Sesal, C., Çobanoğlu, G., Karaltı, İ., Açıkgöz, B. (2016). In Vitro antimicrobial potentials of four Ramalina lichen species from Turkey. Current Research in Environmental \& Applied Mycology6(3), 202-209, Doi 10.5943/cream/6/3/8.

[28] Öztiğitoğlu, G. Ç., Açıkgöz, B., \& Sesal, C. (2017). Lichen secondary metabolites: Synthesis pathways and biological activities. Acta Biologica Turcica, 29(4), 150-163.

[29] Zlatanović, I., Stanković, M., Jovanovic, V. S., Mitić, V., Zrnzević, I., Đorđević, A., \& Stojanović, G. (2017). Biological activities of Umbilicaria crustulosa (Ach.) Frey acetone extract. Journal of the Serbian Chemical Society, 82(2), 141.

[30] Sundararaj, J. P., Kuppuraj, S., Ganesan, A., Ponnusamy, P., \& Nayaka, S. (2015). In vitro assesssment of antioxidant and antimicrobial activities of different solvent extracts from lichen Ramalina nervulosa. International Journal of Pharmacy and Pharmaceutical Sciences, 8(8), 200-204.

[31] Oran, S., Şahin, S., Öztürk, Ş., Demir, C. (2012). Bazı dalsı ve yapraksı liken türlerinde toplam fenol ve antioksidan kapasite tayini. 21. Ulusal Biyoloji Kongresi, 03-07 Eylül 2012, Ege Üniversitesi, İzmir, Türkiye. 